\title{
Job-Ecuador 2.0: Aplicación tecnológica jurídica informativa a nivel laboral en
} el Ecuador

\section{Job-Ecuador 2.0: Informative legal technological application at the labor level} in Ecuador

\author{
Luis Crespo-Berti \\ ui.luiscrespo@uniandes.edu.ec \\ Universidad Regional Autónoma de los Andes, Ibarra \\ Ecuador \\ https://orcid.org/0000-0001-8609-4738 \\ Farid Montenegro-Castillo \\ di.faridemc68@uniandes.edu.ec \\ Universidad Regional Autónoma de los Andes, Ibarra \\ Ecuador \\ https://orcid.org/0000-0002-9366-7415 \\ Lady Dayana Erazo-Insuasti \\ di.ladydei97@uniandes.edu.ec \\ Universidad Regional Autónoma de los Andes, Ibarra \\ Ecuador \\ https://orcid.org/0000-0002-1259-565X
}

Recepción: 15 de septiembre 2021

Revisado: 25 octubre 2021

Aprobación: 15 de noviembre 2021

Publicación: 01 de diciembre 2021 


\section{Estimado Editor (a):}

En los últimos 10 meses, los mercados laborales de América Latina y el Caribe han retrocedido al menos 10 años y la crisis está lejos de terminar, alertó la Organización Internacional del Trabajo (OIT). La tasa de desempleo es de 10,6\% a finales del año 2020 e inicios del 2021, esto implica que el número de personas en busca de trabajo aumentó de 5,4 millones a 30,1 millones, advirtió la organización, cuya oficina para América Latina y el Caribe está en Lima. Si se compara la situación de Ecuador con otros países de América Latina, organismos como la Organización Internacional del Trabajo (OIT) proyectaron para el 2021 un crecimiento económico inferior. Cifras más, cifras menos, lo cierto es que Ecuador no está exento de la crisis económica y laboral que enfrentan muchos países de la región, ello se evidencia en población desempleada o subempleada que reclama mejores condiciones laborales, todo esto se ve reflejado por la pandemia a causa del Sars Cov 2 (Covid-19)

En este sentido, la estabilidad laboral en cualquier país es un aspecto trascendental para su desarrollo por cuanto ello incide positivamente en la disminución de desigualdades de ingresos, en mejorar la protección social y en reducir el peso de la economía informal. Asimismo, un mercado laboral robusto impulsa el ascenso social de la pobreza hacia la no pobreza, lo que en definitiva se traduce en calidad de vida para la sociedad.

Por lo tanto, en este escenario encontrar mecanismos de atención para la protección de la Población Activa de Ecuador es una prioridad; ello involucra a quienes están en edad laboral y bien pueden gozar de un empleo, pero confrontan problemas de violación de sus derechos, o bien se encuentran en búsqueda de empleo, población mayoritariamente joven y sus demandas no son satisfechas, por lo que pueden engrosar la fila de los desempleados o se convierten en subempleados. Además, por la situación de la pandemia en el país se ha visto reflejado el despido intempestivo, es decir de manera violenta sin previo aviso, visto esto se vulneran los derechos de los trabajadores. Ámbito en el que adquiere relevancia el Derecho Laboral por cuanto es una necesidad dar a conocer lo establecido al respecto en la Constitución de la 
República del Ecuador, en el Código del Trabajo, y en todas las normas supletorias que tengan que ver con el acceso al trabajo.

Es necesario destacar, que el trabajo es el sustento de la vida del ser humano, a nivel mundial se puede decir que todas las personas realizan esta actividad. El trabajo tiene muchas definiciones, una de ellas es: el "esfuerzo humano aplicado a la producción de riqueza" (Diccionario RAE, 1780) El trabajo, entonces es una actividad o un esfuerzo humano, gracias a esa actividad se crea satisfacciones materiales los cuales permiten el transcurso de la vida, también aquí entra la intervención del Estado como órgano regulador y controlador de esta actividad humana. Es un área esencial que siempre se relaciona con una necesidad, en consecuencia, todo tipo de trabajo tiene que generar un bien o un servicio, asimismo, constituye uno de los factores productivos, junto con la tierra y el capital.

Se recalca que Ecuador es uno de los países en donde se encuentra muy regulada la situación laboral, en diferentes instrumentos jurídicos. Existen muchos derechos para los trabajadores y así mismo se indican las formas de como el empleador tiene que contratar a sus empleados y bajo qué requisitos. Además, se puede encontrar un concepto muy especificado en la Constitución de la República del Ecuador (2008) específicamente lo siguiente:

Artículo. 33.- El trabajo es un derecho y un deber social, y un derecho económico, fuente de realización personal y base de la economía. El Estado garantizará a las personas trabajadoras el pleno respeto a su dignidad, una vida decorosa, remuneraciones y retribuciones justas y el desempeño de un trabajo saludable y libremente escogido o aceptado.

En el país de Ecuador la Constitución de la República es la máxima norma ecuatoriana en la cual se encuentra el derecho laboral, así mismo funciona como norma supletoria dentro de esta materia, es así que todos los actos que violenten todos los derechos y disposiciones que se encuentran tipificados en la carta magna serán actos inconstitucionales, entonces, se procede a identificar los artículos en donde se encuentran los principios derechos y garantías relevantes al derecho laboral, los cuales son: Art. 11 nums. 2 y 5. Art. 33, Art. 34. Art. 66 nums. 2, 15, 16, 17. Art. 76 núm. 1; y desde el Art. 325 al Art. 333. 
En cada artículo mencionado se trata el tema del derecho laboral como derecho, principio o garantía, realizando un análisis de manera general acerca de esta materia con relación a la Constitución, se puede determinar la construcción de una nueva sociedad que respeta, en todas sus dimensiones, la dignidad de las personas y colectividades, donde impere la justicia y la igualdad, además de la igualdad de condiciones; en la que se consoliden valores de libertad, independencia, paz, solidaridad, el Buen Vivir, la integridad territorial; en la que se asegure el derecho a la vida, al trabajo, a la cultura, a la educación, a la justicia social y a la igualdad sin discriminación ni subordinación alguna. De igual forma, en materia de derechos y garantías constitucionales, las servidoras y servidores públicos administrativos o judiciales, deberán aplicar la norma y la interpretación que más favorezcan su efectiva vigencia.

En tal sentido, el derecho a la seguridad social es un derecho irrenunciable de todas las personas, y será deber y responsabilidad primordial del Estado. La seguridad social se regirá por los principios de solidaridad, obligatoriedad, universalidad, equidad, eficiencia, subsidiaridad, suficiencia, transparencia y participación, para la atención de las necesidades individuales y colectivas. Además, constituye el derecho a una vida digna, que asegure la salud, alimentación y nutrición, agua potable, vivienda, saneamiento ambiental, educación, trabajo, empleo, descanso y ocio, cultura física, vestido, seguridad social y otros servicios sociales necesarios. El derecho a desarrollar actividades económicas, en forma individual o colectiva, conforme a los principios de igualdad de condiciones, solidaridad, responsabilidad social y ambiental. Así mismo, el Estado garantizará el derecho al trabajo. Se reconocen todas las modalidades de trabajo, en relación de dependencia o autónomas, con inclusión de labores de autosustento y cuidado humano; y como actores sociales productivos, a todas las trabajadoras y trabajadores. Por ello, el artículo 326, de la Constitución de la República del Ecuador (2008), es donde se encuentran todos los principios y garantías en materia laboral, aquí se sustenta el derecho del trabajo, conformando 16 principios, como: el induvio pro-operario, los derechos de los trabajadores son irrenunciables e intangibles, igual trabajo igual remuneración, labores en un ambiente 
sano, libertad de organización, derecho a la huelga, validez de transacción, entre otros principios.

Por último, se tiene el artículo 331, de la Constitución de la República del Ecuador (2008). El Estado garantizará a las mujeres igualdad en el acceso al empleo, a la formación y promoción laboral y profesional, a la remuneración equitativa, y a la iniciativa de trabajo autónomo. Se adoptarán todas las medidas necesarias para eliminar las desigualdades. Se prohíbe toda forma de discriminación, acoso o acto de violencia de cualquier índole, sea directa o indirecta, que afecte a las mujeres en el trabajo.

Sin embargo, se dan algunas vulneraciones al derecho laboral, de manera que el despido intempestivo es la terminación de la relación laboral, realizada de manera unilateral por parte del empleador, dicho en otras palabras, es el aviso mediante el cual, el empleador le hace conocer al trabajador, que es su voluntad dar por terminada la relación laboral. El empleador que despida intempestivamente al trabajador, será condenado a indemnizarlo, de conformidad con el tiempo de servicio y según una escala determinada en el Código del Trabajo, las indemnizaciones por despido, podrán ser mejoradas por mutuo acuerdo entre las partes, mas no por los Tribunales de Conciliación y Arbitraje donde se dará por terminadas las relaciones laborales, se dispondrá el reintegro inmediato del trabajador a sus labores.

Al respecto, la terminación de las relaciones laborales de manera intempestiva, súbita, sin antes comunicar al empleado del despido, trae problemas legales para el empleador. Entre ellas la indemnización de acuerdo al tiempo de servicio prestado y con base en la escala que se encuentra en el artículo 188 del Código del Trabajo. El derecho ecuatoriano es Progresivo, ya que por mandato Constitucional:

Artículo 11, numeral 8. El contenido de los derechos se desarrollará de manera progresiva a través de las normas, la jurisprudencia y las políticas públicas" (Asamblea Nacional Constituyente, 2008)

Lo que trae como consecuencia, la penalización como inconstitucional cualquier acción u omisión de carácter regresivo que disminuya, o anule injustificadamente el ejercicio de los derechos. Este tipo de despido se ha dado a lo largo de la pandemia 
en varios lugares del país, como por ejemplo las florícolas de Tabacundo, se ha conocido, testimonios de ex trabajadores que cuentan cómo fue la forma de despido de una forma violenta, para colmo del despido reciben una miserable liquidación que no fue justa por los años de trabajo. En el auge de la pandemia los Gobiernos asumieron la difícil tarea de enfrentar a la enfermedad y buscar mecanismos para evitar la propagación. Pero no fue suficiente estás acciones, debido a que existieron otros inconvenientes como la alteración de las relaciones jurídicas públicas y privadas en un sentido totalmente negativo que necesitaban urgentemente medidas para encauzarse y retomar el orden y la normalidad.

Por esta razón, la Función Ejecutiva de Ecuador envío un Proyecto de Ley calificado de urgencia en materia económica a la Asamblea Nacional para mitigar la crisis sanitaria, económica y social que provocó el Covid-19, buscando fomentar la reactivación económica y productiva del Ecuador, con especial énfasis en el ser humano. La Ley Humanitaria fue aprobada por la Asamblea y está compuesta por cuatro capítulos, siete disposiciones generales, cuatro disposiciones derogatorias y una disposición interpretativa referente al artículo 169 numeral 6 del Código de Trabajo por la terminación de la relación laboral por caso fortuito o fuerza mayor además de 23 disposiciones transitorias.

Al parecer se puede pensar que, si es para apoyar a la sociedad ecuatoriana, sin embargo, no es así, ya que al irrumpir en la derogatoria y en específico y una disposición interpretativa referente al artículo 169 numeral 6 del Código de Trabajo, varias empresas se han tomado de ese artículo y han hecho de las suyas al interpretar y perjudicar a los trabajadores despidiéndolos unilateralmente, violentado los derechos laborales. Es una necesidad que los involucrados atiendan no solo el desempleo, sino también aquellas categorías adicionales del empleo porque la meta del mercado laboral no debe ser solo alcanzar una "tasa de desempleo natural" (Olmedo, 2018, p.40) sino lograr condiciones cada vez más favorables para la población, lo que requiere se atienda el sub empleo y otros tipos de empleo no del todo satisfactorios. 
La discusión anterior, permite comprender la trascendencia que tienen las variables que intervienen en los mercados laborales y su incidencia en la calidad de vida de la población pues tener estabilidad laboral es vital, en consecuencia, resulta de gran utilidad valerse de la tecnología para ofrecer información a la población activa en aspectos como: instrumentos jurídicos que garantizan derechos y obligaciones a los trabajadores, ofertas laborales, tendencias de los mercados, profesiones más demandadas, entre otros. En Ecuador, la Constitución de la República (2008), en el Artículo 326, se encuentran reconocidos los derechos a los trabajadores; posición de la que se derivan otras leyes y políticas para su aplicación en la sociedad.

\section{FINANCIAMIENTO}

No monetario.

\section{AGRADECIMIENTO}

A la Universidad Regional Autónoma de los Andes, Ibarra, por motivar el desarrollo de la Investigación.

\section{REFERENCIAS CONSULTADAS}

Asamblea Nacional de la República del Ecuador (2020). Ley Orgánica de apoyo humanitario. [Organic Law on Humanitarian Support]. Registro Oficial Suplemento 229 de 22-jun.-2020. https://n9.cl/8yi7

Asamblea Nacional Constituyente de la República del Ecuador, (2008). Constitución de la República del Ecuador. [Constitution of the Republic of Ecuador]. Montecristi. Registro Oficial 449 de 20-oct-2008. Recuperado de https://n9.cl/sia

Congreso Nacional. (2005). Código del Trabajo. [Work code]. Codificación 17 Registro Oficial Suplemento 167 de 16-dic.-2005. Recuperado de: https://n9.cl/652cf

Instituto Nacional de Estadística y Censos (2019). Encuesta Nacional de empleo, desempleo y subempleo (ENENDU). [National Survey on Employment, Unemployment and Underemployment (ENENDU)]. Boletín Técnico № 02- 2019. Quito: ENEMDU. Recuperado de: https://n9.cl/ymsx1 
Olmedo. P. (2018). El empleo en el Ecuador - Una mirada a la situación y perspectivas para el mercado laboral actual. [Employment in Ecuador - A look at the situation and prospects for the current labour market]. Quito. Fiedrich- Ebert- Shiftung. Recuperado de: https://n9.cl/ymsx1

Organización Internacional del Trabajo (2021). Transitando la crisis laboral por la pandemia: hacia una recuperación del empleo centra en las personas. [Navigating the labor crisis due to the pandemic: towards a recovery of employment focused on people]. Recuperado de: https://n9.cl/cl7zg

Convenio 169 de la OIT sobre pueblos indígenas y tribales. [ ILO Convention 169 on Indigenous and Tribal Peoples]. Recuperado de: https://n9.cl/jkso

Real Academia Española (1780) Diccionario de la Real Academia Española. [Dictionary of the Royal Spanish Academy]. España. Recuperado de: https://n9.cl/g3u79 